Running Head: Threat Rejection Fuels Political Dehumanization

\title{
Threat Rejection Fuels Political Dehumanization
}

\author{
Emily Kubin ${ }^{1,2 *}$, Frank J. Kachanoff ${ }^{2 *}$, \& Kurt Gray ${ }^{2}$
}

\section{This paper is now in press at Social Psychological and Personality Science and is not the final version.}

\footnotetext{
Affiliations:

${ }^{1}$ Department of Psychology, University of Koblenz-Landau

${ }^{2}$ Department of Psychology and Neuroscience, University of North Carolina at Chapel Hill

*Kubin and Kachanoff contributed equally and share first authorship.

Correspondence can be made to Emily Kubin (kubin@uni-landau.de) and Frank Kachanoff (fkach@email.unc.edu)
} 


\begin{abstract}
Americans disagree about many things, including what threats are most pressing. We suggest people morally condemn and dehumanize opponents when they are perceived as rejecting the existence or severity of important perceived threats. We explore perceived "threat rejection" across five studies $(\mathrm{N}=2,404)$ both in the real-world COVID-19 pandemic and in novel contexts. Americans morally condemned and dehumanized policy opponents when they seemed to reject realistic group threats (e.g., threat to the physical health or resources of the group). Believing opponents rejected symbolic group threats (e.g., to collective identity) was not reliably linked to condemnation and dehumanization. Importantly, the political dehumanization caused by perceived threat rejection can be soothed with a "threat acknowledgement" intervention.
\end{abstract}

Key words: Threat Rejection, Moral Condemnation, Dehumanization, Intervention, COVID19 


\section{Threat Rejection Fuels Political Dehumanization}

Humans evolved to be attuned to threats in their physical and social environments (Stephan, et al., 2009). People are driven to protect themselves (and their group) from realistic threats to physical well-being and economic livelihood (Esses, et al., 2001) and from symbolic threats to their values and identity (Kachanoff et al., 2020). But not everyone agrees on what threats are most important-some prioritize physical safety while others prioritize protecting sacred symbols. People even deny the magnitude of another threat, such as when some conservatives deny climate-change-based threats held by liberals. Here we examine the impacts of perceived threat rejection — whether people condemn and dehumanize opponents when they believe their opponents reject the threats (realistic or symbolic) they care most about.

\section{Perceived Threats-and Rejection of Threats}

We explore threat rejection through the lens of COVID-19 which is both a realistic and symbolic threat (Kachanoff et al., 2021), and in artificial contexts. COVID-19 has killed millions and pummeled economies (realistic threat). But the existential threat of the virus, the uncertainty of its long-lasting effects on society, and the strategies to mitigate this threatincluding social distancing that suppress people's ability to express cultural identity through social gatherings, religious services, and political rallies — all cause symbolic threats; Stein, et al., 2020). Debates about pandemic policies are tied to emphasizing the realistic or symbolic threat of COVID-19. While many experience realistic and symbolic threat to COVID-19 simultaneously, those most concerned with realistic threats are most supportive of social distancing, while those most concerned with symbolic threats are most resistant of social distancing (Kachanoff et al., 2020). People often see opponents as rejecting the threats they care about (e.g., pro-social distancers see anti-social distancers as rejecting the lethality of COVID-19, while anti-social distancers see pro-social distancers as rejecting the importance of American liberties). 
We operationalize perceived threat rejection as perceiving opponents disregard a threat, either by dismissing it entirely or ranking it as less severe relative to other threats. Vice President Harris, who supported social distancing policies, condemned former President Trump who opposed social distancing policies as "an individual who is not concerned about the health, safety and well-being of the American people" (Ember, 2020). Simultaneously, President Trump, called governors who supported social distancing "dictators" who seek to destroy Americans' amendment rights (Shear \& Mervosh, 2020).

\section{The Perils of Threat Rejection}

We hypothesize that people morally condemn opponents they perceive to reject important group threats. One adaptive function of moral judgment is to guard ourselves and our groups from harm (Shweder, et al., 1997), and moral judgment is influenced by perceptions of harm (Schein \& Gray, 2018). Therefore, perceiving policy opponents as rejecting imminent threats should foster moral condemnation (Moore-Berg, et al., 2020). But does perceiving an opponent as rejecting a realistic versus symbolic threat lead to the same magnitude of condemnation?

Harms associated with realistic threats are concrete and pertain to immediate physical, psychological, or economic damages. In contrast, harms associated with symbolic threats to a group's identity are abstract and less immediate (Schein \& Gray, 2018). Symbolic threats can indirectly manifest in realistic harms by reducing psychological well-being (Kachanoff, et al., 2019) or disrupting group cohesion or the economy (Abrams \& Milica, 2014; Ritzen, et al., 2000). But this causal chain is indirect and might not always be salient. Given these differences we tested two competing hypotheses: The symmetry hypothesis predicts realistic and symbolic group threat rejection equally drive moral condemnation. This argues that even though symbolic threats are less concrete than realistic threats, they are still viewed by group members as harming important group needs tied to identity (Greenaway et al., 2016) and are thus morally condemned like realistic threats. This is supported by findings that symbolic 
(like realistic) threats influence attitudes and behaviors (Gamez-Djokic \& Waytz, 2020; Kachanoff, et al., 2020; Stein, et al., 2020). In contrast, the asymmetry hypothesis predicts realistic threat rejection is more potent than symbolic threat rejection in eliciting condemnation because the harms associated with realistic threats are more concrete and immediate. This is supported by research showing people condemn an action more when it causes realistic harm (e.g., hitting a child) vs. symbolic harm (disrespecting the American Flag; Schein and Gray, 2018; Gray \& Wegner, 2011).

If perceived threat rejection leads people to morally condemn, then it likely causes people to dehumanize. The relation between condemnation and dehumanization is robust (e.g., Bastian, et al., 2013; Pacilli, et al., 2016). People view morality as a defining quality of "humanness" (Haslam, et al., 2012) and animalistic qualities are associated with immoral behavior (Bandura, 1999). Thus, it is not surprising that during the COVID-19 pandemic, moral condemnation and dehumanization went hand-in-hand when people felt opponents' rejected threats caused by the pandemic. For example, critics called Republican politician Joe Borelli a "selfish" (i.e., immoral) "monster" (i.e., not human) when he defied social distancing guidelines (Moran, 2020). However, in keeping with our distinction between the symmetry versus asymmetry hypothesis it is an open question whether perceived realistic threat rejection leads to greater dehumanization than symbolic threat rejection - if moral condemnation is heightened for realistic versus symbolic threat rejection, than the resulting dehumanization should also be magnified for realistic versus symbolic threat rejection.

Supporting this, people condemn and dehumanize those they perceive pose a realistic threat of physical danger (e.g., terrorists; Kteily, et al., 2015) or economic harm (Louis, et al., 2013). In contrast, people may be less likely to condemn and dehumanize those who reject symbolic threats.

\section{The Promise of Acknowledging Threats}


If perceived threat rejection inflames moral conflict, then perhaps perceived threat acknowledgement can mitigate it. We developed a "hybrid threat acknowledgement intervention," whereby people explained how their position is motivated by concerns about both realistic and symbolic threats. By expressing concerns about both threats, opponents can validate the perceived threats of opponents while staying true to their position—consistent with other successful perspective-taking interventions for intergroup conflict (Galinsky, et al., 2005; Bruneau \& Saxe, 2012). For example, moral framing research (Feinberg \& Willer, 2013, 2015; Kidwell, et al., 2013) finds partisans are supportive of opponents' policies when opponents acknowledge their own values.

A COVID-19 hybrid threat acknowledgement for pro-social distancers would justify their position by mentioning both COVID-19's realistic threat to health and also explaining how failing to protect American lives is a symbolic threat to the American value of unity. Similarly, anti-social distancers would argue against social distancing by raising concerns over symbolic threats to civil liberty and also explaining how symbolic threats are psychologically damaging (realistic threat).

\section{Overview of Present Research}

We tested our hypotheses across 3 studies and 5 samples (including one quasirepresentative sample), using correlational and experimental methods examining COVID-19 and a novel threat. Primary analyses controlled for people's own threat concerns and their political ideology, which both predict the policies people support (e.g., Clinton et al., 2021; Gollwitzer, et al., 2020). Results remain robust without covariates - see Supplementals. Data, materials, and pre-registrations for studies available at: https://osf.io/25buh/?view_only=48faedfd66b7442bad26b34735d12cb8. ${ }^{1}$

\section{Study 1}

\footnotetext{
${ }^{1}$ Studies approved by University of North Carolina-Chapel Hill Institutional Review Board (Studies 1 and 3 No.20-1974;Study 2 No.18-0177).
} 
We hypothesized people who supported social distancing most would see opponents as rejecting realistic threats, while people who were less supportive of social distancing would see opponents as rejecting symbolic threats. We had competing hypotheses (i.e., symmetry and asymmetry hypotheses) for whether realistic more so than symbolic threat rejection would promote condemnation and dehumanization.

Sample. We recruited 326 American Mechanical Turk workers through CloudResearch on June $16^{\text {th }} 2020$. Participants not born in the US or who failed attention checks were excluded (281 participants, $51.96 \%$ male, $\left.\mathrm{M}_{\mathrm{age}}(\mathrm{SD})=38.31(11.79)\right)^{2}$. See Supplemental Table 1 for demographic information.

Procedure and Measures. Participants responded to a survey about the COVID-19 pandemic, see Table 1.

\footnotetext{
${ }^{2}$ Studies 1-3a, participants had HIT ratings $(>95 \%)$ and duplicate IP addresses were blocked. All studies included several attention check measures, those who failed were not included in analyses.
} 
Table 1.

Measures in Study 1.

\begin{tabular}{l} 
Measure \\
\hline Questions in reference to self: \\
Support for Social Distancing. \\
Strongly Disagree (1) to \\
Strongly Agree $(7)(\alpha=.96)$ \\
Personal Perceptions of Realistic \\
Threat. Not a threat (1) to Major \\
Threat $(4)^{3}(\alpha=.68)$
\end{tabular}

Personal Perceptions of Symbolic Threat. Not a threat

(1) to Major Threat (4) $(\alpha=.91)$

Political Ideology. Very Liberal

(1) to Very Conservative (7) $(\alpha=.95)$

\section{Items}

10 items. Examples: "Stay-at-home orders should be in place", "Non-essential businesses should stay closed", "Schools and daycares should stay closed"

Prompt: "How much of a threat, if any is the Coronavirus outbreak for..."

5 items. Examples: "Your personal health", "The U.S. economy"

Prompt: "How much of a threat, if any is the Coronavirus outbreak for..."

5 items. Examples: "What it means to be American", "American values and traditions"

3 items: "In general, how would describe your political orientation?", "In terms of economic issues, how would describe your political attitudes and beliefs?", "In terms of social issues, how would describe your political attitudes and beliefs?"

\section{Questions in reference to opponents:}

Opponent Rejection of Realistic 3 items. "Doesn't care if thousands of Americans die", Threat. Not at All (1) to Very Much So (5) $(\alpha=.82)$

"Doesn't care if thousands of Americans lose their livelihoods", "Doesn't care about protecting American lives"

Opponent Rejection of Symbolic Threat. Not at All (1) to Very Much So (5) $(\alpha=.93)$

Opponent Moral Condemnation Not at All (1) to Very Much So (5) $(\alpha=.81)$

Opponent Dehumanization Not at All (1) to Extremely (7) $(\alpha=.81)$
3 items. "Doesn't care if American rights and freedoms are lost forever", "Doesn't care if the essence of what it means to be American is destroyed", "Doesn't care about protecting American identity"

4 items. "Completely immoral", "fundamentally wrong", "absolutely shameful”, "morally correct” (R)

8 items. Examples: "Mechanical and cold, like a robot", "Emotional, like they are responsive and warm" (R), "Lacking self-restraint, like an animal"

Note: (R) indicates reverse coded item. Reliability analyses for personal realistic threat concern was lower than anticipated. Exploratory factor analyses indicated that a one factor loading was appropriate. See Supplemental Figure 1.

\footnotetext{
${ }^{3}$ Personal perceptions of realistic and symbolic threat adapted from Kachanoff et al. (2021).

${ }^{4}$ Dehumanization adapted from Bastian et al., (2013).
} 


\section{Results}

Replicating Kachanoff and colleagues (2021), personally perceiving COVID-19 as a realistic threat was associated with greater social distancing support while perceiving COVID-19 as a symbolic threat was associated with less social distancing support (see Table 2). Personal symbolic and realistic threat concerns were positively associated with each other, and the partial correlations between social distancing support and personal symbolic $(r=-0.31$, $\mathrm{p}<.001)$ and realistic $(r=0.47, \mathrm{p}<.001)$ threat concerns increased in magnitude, when accounting for the other type of threat concern.

Supporting social distancing predicted beliefs that opponents rejected realistic threats. However, social distancing support was unrelated to symbolic threat rejection. Supporting social distancing predicted greater moral condemnation and dehumanization of opponents. Table 2.

Means, reliabilities and inter-correlations for Study 1.

\begin{tabular}{|c|c|c|c|c|c|c|c|c|c|}
\hline & Mean(SD) & $\alpha$ & 1. & 2. & 3. & 4. & 5. & 6. & 7. \\
\hline $\begin{array}{l}\text { 1. Participant } \\
\text { Stance on Social } \\
\text { Distancing }\end{array}$ & $4.42(1.33)$ & -- & & & & & & & \\
\hline $\begin{array}{l}\text { 2. Perception of } \\
\text { Opponent } \\
\text { Rejection of } \\
\text { Realistic Threat }\end{array}$ & $2.92(1.26)$ & 0.82 & $0.54 * * *$ & & & & & & \\
\hline $\begin{array}{l}\text { 3. Perception of } \\
\text { Opponent } \\
\text { Rejection of } \\
\text { Symbolic Threat }\end{array}$ & $2.44(1.32)$ & 0.93 & 0.07 & $0.57 * * *$ & & & & & \\
\hline $\begin{array}{l}\text { 4. Moral } \\
\text { Condemnation }\end{array}$ & $3.18(1.16)$ & 0.81 & $0.35 * * *$ & $0.59 * * *$ & $0.35^{* * *}$ & & & & \\
\hline $\begin{array}{l}\text { 5. Opponent } \\
\text { Dehumanization }\end{array}$ & $4.55(1.24)$ & 0.81 & $0.41 * * *$ & $0.67 * * *$ & $0.33^{* * *}$ & $0.57 * * *$ & & & \\
\hline $\begin{array}{l}\text { 6.Participant } \\
\text { Perception of } \\
\text { Realistic Threats }\end{array}$ & $3.04(0.57)$ & 0.68 & $0.40 * * *$ & $0.25 * * *$ & 0.07 & $0.12 *$ & $0.27 * * *$ & & \\
\hline $\begin{array}{l}\text { 7.Participant } \\
\text { Perceptions of } \\
\text { Symbolic } \\
\text { Threats }\end{array}$ & $2.34(0.90)$ & 0.91 & $-0.15^{*}$ & -0.08 & $0.37 * * *$ & -0.08 & $-0.16^{* *}$ & $0.30 * * *$ & \\
\hline
\end{tabular}




\begin{tabular}{llllllllll}
$\begin{array}{l}\text { 8. Participant } \\
\text { Ideology }\end{array}$ & $-0.40(1.83)$ & 0.95 & $-0.37 * * *$ & $-0.26 * * *$ & 0.07 & $-0.23 * *$ & $-0.31 * * *$ & -0.09 & $0.43 * * *$ \\
\hline
\end{tabular}

Note: $* * * \mathrm{p}<.001, * * \mathrm{p}<.01, * \mathrm{p}<.05$. Social distancing stance does not include reliability analysis as this measure was 1 -item.

Threat Rejection, Condemnation and Dehumanization. SEM-path modeling examined whether differences in moral condemnation and dehumanization based on social distancing stance were due to differences in perceived realistic versus symbolic threat rejection. We tested a serial mediation model where social distancing stance predicted perceptions of realistic and symbolic threat rejection, which in turn predicted moral condemnation and dehumanization. Effects for paths are summarized in Figure 1 (see p.4 of Supplementary Materials).

Support for social distancing was associated with greater perceived realistic threat rejection, which predicted greater moral condemnation and dehumanization, serial indirect effect $=0.07, \mathrm{SE}=0.02,95 \% \mathrm{CI}[0.03,0.12]^{5}$. Supporting social distancing also predicted greater perceived symbolic threat rejection (i.e., the non-significant zero-order relation became significant accounting for ideology and people's own belief that COVID-19 posed a realistic/symbolic threat). There was no indirect effect of social distancing stance on dehumanization through symbolic threat rejection and moral condemnation, serial indirect effect $=0.003, \mathrm{SE}=0.005,95 \% \mathrm{CI}[-0.01,0.01]$. This is because symbolic threat rejection did not relate to condemnation or dehumanization. The total effect $(\mathrm{B}=0.24, \mathrm{SE}=0.005,95 \%$ $\mathrm{CI}[0.11,0.37])$ of social distancing stance on dehumanization was significant while the direct effect was not $(\mathrm{B}=-0.05, \mathrm{SE}=0.05,95 \% \mathrm{CI}[-0.15,0.05])$.

\footnotetext{
${ }^{5}$ All 95\% CIs for indirect effects are bootstrapped for 5,000 iterations.
} 


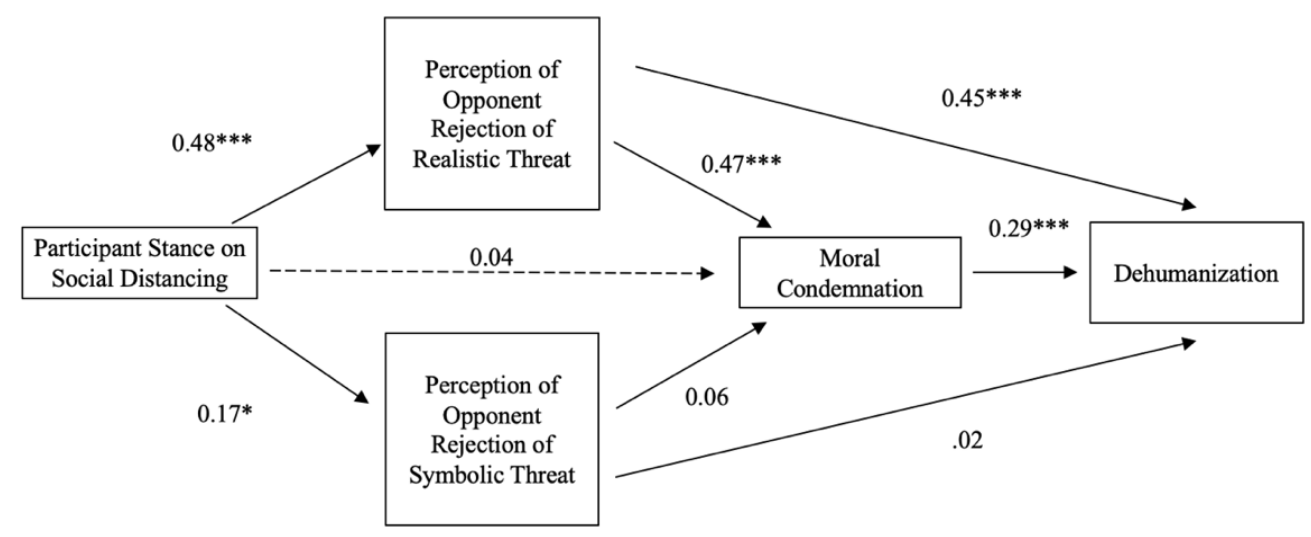

Figure 1: SEM analyses for Study 1. Social distancing stance entered as continuous variable. Although not drawn in the model, we included participant ideology and participants' perceptions of realistic and symbolic threat as exogenous covariates acting on all paths. $* * *$ indicates $p<.001, *$ indicates $p<.05$. Path coefficients are unstandardized. The order of variables in this model (and other path models reported in the manuscript) is only one of several path models that could have been tested and thus cannot infer causality given that constructs were assessed cross-sectionally.

\section{Discussion}

Study 1 indicated perceived threat rejection increased moral condemnation and dehumanization but only for those who perceived rejection of realistic threats by opponents, supporting the asymmetry hypothesis. Moral condemnation mediated the link between perceived rejection of realistic threats and dehumanization. Social distancing support was associated with less personal concern for symbolic threat but was unrelated to perceiving opponents as rejecting symbolic threat (zero-order correlation). This relationship became significant and positive when accounting for covariates. It is possible that people who support social distancing perceive people who are less supportive of social distancing as disregarding the American value of protecting American lives (i.e., symbolic threat rejection; Whiting, 2020). 


\section{Study 2: A Novel Case of Realistic (Versus Symbolic) Threat Rejection}

Study 1 revealed how perceived (realistic) threat rejection predicts moral condemnation and dehumanization during the COVID-19 pandemic. However, because this issue is tied to ideology (Clinton et al., 2021), it is important to rule out the effect of partyidentity that can also drive moral condemnation and dehumanization (Cassese, 2020; Martherus, et al., 2021). Additionally, in the COVID-19 context, realistic threat rejection involved denying the extreme harm of death. Thus, the unique effect of realistic threat rejection driving condemnation and dehumanization might have been due to an imbalance in the magnitude of the realistic versus symbolic threat. Finally, the COVID-19 pandemic simultaneously elicited two forms of realistic threat - the physical threat of disease and the material threat of economic collapse (Kachanoff et al., 2021). Thus, it remains unclear whether both physical and material threat rejection promote condemnation and dehumanization. To address these concerns, we created a novel context that (1) was less tied to political party affiliation, (2) balanced in the magnitude of realistic and symbolic threats, and (3) considered whether the realistic threat was to physical health or material resources.

Participants imagined they were town members whose cultural identity was tied to the cultivation of a flower, but that growing it caused severe allergies and asthma (i.e., physical realistic threat less severe than death; Study $2 a$ ) or economic hardship (i.e., material realistic threat; Study 2b). Participants chose between mitigating the realistic threat (protecting health/economy by banning the flower) or the symbolic threat (protecting identity/customs by keeping the flower). We tested whether policy position predicted perceptions that policy opponents rejected realistic versus symbolic threats, and in turn, moral condemnation and dehumanization 6 .

\section{Sample}

\footnotetext{
${ }^{6}$ Main-text analyses controlled for participants' own ideology and threat concerns, but the model was robust controlling for participants' belief about opponents' ideology (See Figure S4 and S6, e.g.,.:"Please rate how liberal or conservative you think Thomas is").
} 
Study 2a. We recruited 404 American Mechanical Turk workers through CloudResearch on June $23^{\text {rd }}$ 2021. Participants who failed attention checks were excluded, (363 participants, 39.39\% male, $\mathrm{M}_{\mathrm{age}}(\mathrm{SD})=41.63(13.73)$ ). See Supplemental Table 2 for demographic information.

Study 2b. We recruited 405 American Mechanical Turk workers through CloudResearch on June $29^{\text {th }}$ 2021. Participants who failed attention checks were excluded, (372 participants, $45.16 \%$ male, $\mathrm{M}_{\mathrm{age}}(\mathrm{SD})=40.34(13.57)$ ). See Supplemental Table 4 for demographic information.

Procedure and Measures. Participants read about the cultural significance of the flower and the debate to ban flower cultivation after it was linked to severe allergies and asthma (Study 2a, see Supplemental Materials p.7) or after climate change made flower cultivation so expensive it caused financial hardship (Study 2b, see Supplemental Materials p.13). Participants rated their stance on whether the flower should be banned from 1(strongly oppose) to 6(strongly support), and then rated threat rejection, moral condemnation, and dehumanization of a person with an opposing view on the ban. Finally, participants rated their perceived threat of the dilemma, and their political ideology. See Tables S3 and S5 for all scale items, reliabilities, and descriptive statistics across both sub-studies. In Study 2a, 210 participants opposed banning cultivation (57.85\%) and 153 supported banning it (42.15\%). In Study 2b, 189 participants opposed banning cultivation (50.81\%) and 183 supported banning it $(49.19 \%)$.

\section{Results}

Participants' concern of realistic threats was associated with support for the cultivation ban, while participants' concern for symbolic threat was associated with opposing the ban. In Study 2a, those who supported the ban were more likely to be liberal—-though this was a small correlation, $r(353)=-0.13, p=.015$. Stance was not related to ideology in Study $2 \mathrm{~b}$ $r(360)=-0.02, p=.74$, suggesting a politically neutral context (See Table S3 \& S5). 
People viewed opponents as rejecting the threats they cared about. Participants most supportive of the ban believed opponents rejected realistic threats, while those most opposed believed opponents rejected symbolic threats. Supporting the ban was positively associated with condemnation and dehumanization (See Table S3 \& S5).

Threat Rejection, Condemnation and Dehumanization. A SEM-path model examined whether differences in perceived realistic and symbolic threat rejection explained differences in condemnation and dehumanization among supporters versus opposers of the cultivation ban. We tested whether people's stance on the ban predicted perceptions of realistic and symbolic threat rejection, and subsequently moral condemnation and dehumanization. Effects for paths are summarized in Figure 2 (see Supplemental Materials p.9 \& 15).

Supporting the cultivation ban was associated with greater perceived realistic threat rejection, which predicted greater moral condemnation and dehumanization, (serial indirect effect $_{\text {Study } 2 a}=0.12, \mathrm{SE}=0.02,95 \% \mathrm{CI}[0.08,0.16]$; serial indirect effect Study $_{2 b}=0.14, \mathrm{SE}=0.02$, $95 \% \mathrm{CI}[0.09,0.18])$. In contrast, opposing the ban predicted greater symbolic threat rejection leading to greater condemnation and dehumanization, (serial indirect effect $t_{\text {Study } 2 a}=-0.03$, $\mathrm{SE}=0.01,95 \% \mathrm{CI}[-0.05,-0.009]$; serial indirect effect $_{\text {Study }} 2 b=-0.02, \mathrm{SE}=0.006,95 \% \mathrm{CI}[-0.03,-$ $0.007])$.

Supporting the asymmetry hypothesis, the condemnation and dehumanization pathway was significantly smaller for symbolic versus realistic threat rejection (serial difference $_{\text {Study } 2 a}=0.09, \mathrm{SE}=0.02,95 \% \mathrm{CI}[0.04,0.14]$; serial difference Study $2 b=0.12, \mathrm{SE}=0.02$, $95 \%$ CI $[0.08,0.17])$. This explains why there was a significant total effect of supporting the ban on dehumanization (Study $2 \mathrm{a}: \mathrm{B}=0.25, \mathrm{SE}=0.05,95 \% \mathrm{CI}[0.16,0.35]$; Study $2 \mathrm{~B}: \mathrm{B}=0.21$, $\mathrm{SE}=0.04,95 \% \mathrm{CI}[0.13,0.29])$. The direct effect of stance on dehumanization when 
accounting for threat rejection was not significant (Study $2 \mathrm{a}: \mathrm{B}=0.05, \mathrm{SE}=0.05,95 \% \mathrm{CI}[-0.05$, 0.14]; Study $2 \mathrm{~b}: \mathrm{B}=-0.05, \mathrm{SE}=0.04,95 \% \mathrm{CI}[-0.12,0.03])$.

Panel A.

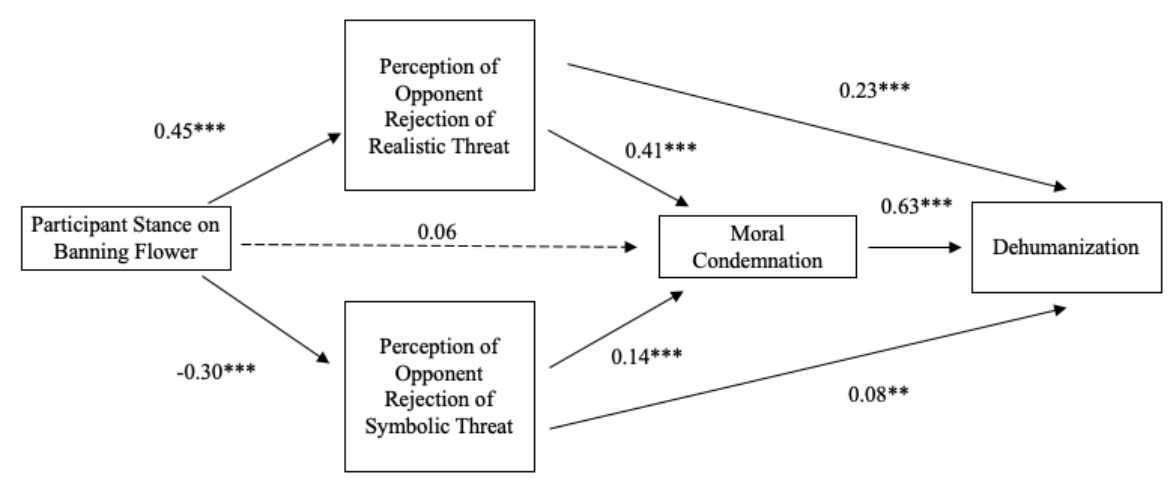

Panel B.

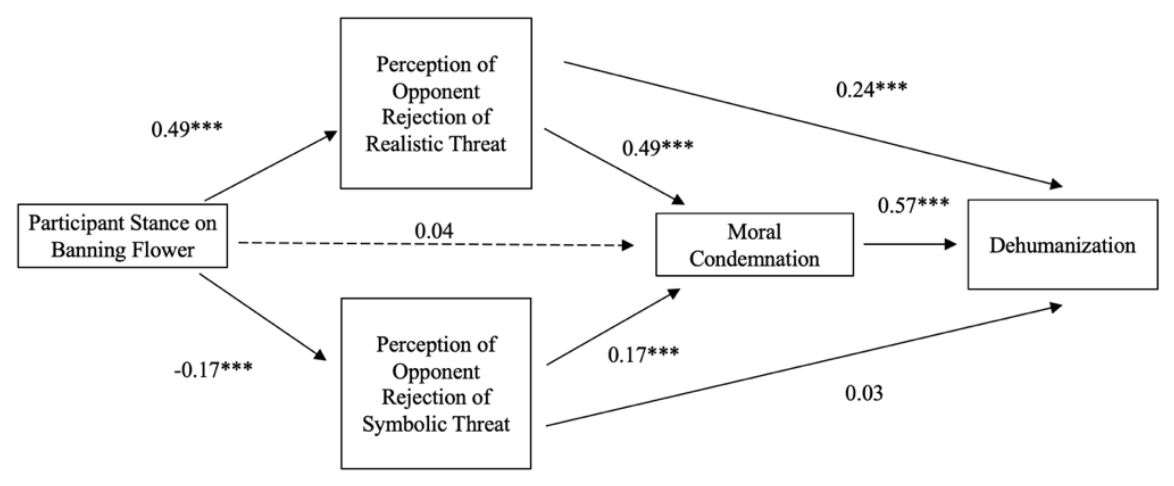

Figure 2: SEM analyses for Study 2a (physical realistic threat) (Panel A) and Study 2b

(material realistic threat) (Panel B). Although not drawn in the model, we included participant ideology and participants' perceptions of realistic and symbolic threat at exogenous covariates acting on all paths. Cultivation ban stance entered as continuous variable, *** indicates $p<.001$. Path coefficients are unstandardized.

\section{Discussion}

Results replicated Study 1 within a novel context that reduced the potential influence of political identity. People more willing to sacrifice their group's culture (symbolic threat) to protect against realistic threat (either to the group's physical health or resources) were more likely to assume their opponents rejected realistic threat, leading to greater condemnation and dehumanization. Unlike Study 1, people more willing to endure realistic threats to protect 
their culture assumed their opponents rejected symbolic threat, which was also positively associated with moral condemnation and dehumanization. However, still supporting the asymmetry hypothesis, the relative effect of realistic (versus symbolic) threat rejection on condemnation and dehumanization was significantly stronger.

\section{Study 3: A Threat Acknowledgement Intervention for Reducing Dehumanization}

In Study 3, we returned to the COVID-19 context to test our threat acknowledgement intervention. We showed people an opponent's rationale for their social distancing stance that was either motivated by concerns about symbolic and realistic threat (i.e., the hybrid threat acknowledgement condition) — which we predicted to be more effective at reducing condemnation and dehumanization — versus only one type of threat concern that is commonly linked to the oppositions' stance (i.e., a typical threat condition in which anti-social distancers were concerned about symbolic threats and pro-social distancers were concerned about realistic health threats). We also considered a no rationale condition where the opponent provided no reasoning for their stance.

Using a moderation framework, we tested whether the threat acknowledgement intervention was effective for people who were relatively pro (versus) anti-social distancing. Because Studies 1-2 suggested that the perceived rejection of realistic (versus symbolic) threat was most likely to predict condemnation and dehumanization, we suspected the hybrid threat acknowledgement may be most effective for people most supportive of social distancing as they were most likely to condemn and dehumanize opponents.

\section{Sample.}

Study 3a. We recruited 609 American Mechanical Turk workers through CloudResearch on September $29^{\text {th }} 2020$. Participants not born in the US or who failed attention checks were excluded, (570 participants, 44.56\% male, $\left.\mathrm{M}_{\text {age }}(\mathrm{SD})=38.96[18.23]\right)$. See Supplemental Table 6 for demographic information. 
Study 3b. We collected a quasi-representative sample of $1,350^{7}$ American participants (40\% Republican, $40 \%$ Democrat, and $20 \%$ Independent) from October $28^{\text {th }}$-November $16^{\text {th }}$ 2020 using Lucid Panels. Those not born in the US or who failed attention checks were excluded, (818 participants, 33.74\% male, $\mathrm{M}_{\mathrm{age}}(\mathrm{SD})=50.08(16.30)$ ). See Supplemental Table 9 for demographic information

Procedure and Measures. Participants reported their agreement with the following statement, "Social distancing rules should be strict (i.e., schools, bars and gyms should be closed) until we have a vaccine", using a 6-point scale from Strongly Disagree(1) to Strongly Agree(6). Participants scoring 1 to 3 learned about a pro-social distancer while participants scoring 4 to 6 learned about an anti-social distancer. Participants were randomly assigned to one of the 3 rationale conditions (see Table 3 ).

\footnotetext{
${ }^{7}$ We pre-registered recruiting 1200 participants - however Lucid oversampled by 150 participants which is customary for panel surveys to meet quotas and ensure enough good completes.
} 
Table 3.

Vignettes read by participants in Studies $3 a$ and $3 b$.

\begin{tabular}{ccc}
\hline Manipulations & $\begin{array}{c}\text { Vignettes for relatively pro-social } \\
\text { distancing participants reading about } \\
\text { an anti-social distancing opponent }\end{array}$ & $\begin{array}{c}\text { Vignettes for relatively anti-social } \\
\text { distancing participants reading about } \\
\text { a pro-social distancing opponent }\end{array}$ \\
\hline
\end{tabular}

No Rationale

(Control)

Typical Threat Rationale

Hybrid Threat Acknowledgement
Thomas disagrees with your stance on social distancing measures. He does not support social distancing measures.

Thomas disagrees with your stance on strict social distancing measures. He does not support strict social distancing measures because he wants to protect American values. He truly believes that strict social distancing measures, like restrictive stay-at-home policies, go against core American values. $\mathrm{He}$ idealizes the value of American freedom and independence, and the old American way of life, and believes these policies would take that away.

Thomas disagrees with your stance on strict social distancing measures. He does not support strict social distancing measures because he wants to protect Americans from harm. He truly believes that strict social distancing measures, like restrictive stay-at-home policies, will destroy the lives and livelihoods of thousands of Americans because of the psychological trauma he thinks will be caused to Americans who will lose their freedom, and have to cope with their old American way of life being completely changed.
Thomas disagrees with your stance on social distancing measures. He supports social distancing measures.

Thomas disagrees with your stance on strict social distancing measures. He supports strict social distancing measures because he wants to protect Americans from harm. He truly believes that strict social distancing measures, like restrictive stay-at-home policies, will protect the lives and livelihoods of thousands of Americans because he thinks the spread and death-toll of the virus cannot be contained without such measures.

Thomas disagrees with your stance on strict social distancing measures. He supports strict social distancing measures because he wants to protect American values. He truly believes that strict social distancing measures, like restrictive stay-at-home policies, resonate with core American values. $\mathrm{He}$ idealizes the value of Americans coming together as one Nation to make tough sacrifices for the greater good by protecting people from harm. 


\section{Results}

Intervention Effectiveness for Pro and Anti Social Distancers. Using the PROCESS macro (Hayes, 2018; model 1) we tested whether the Hybrid Threat Acknowledgement intervention had differential effects for people who were relatively supportive of versus against social distancing (See Figure 3, Table 4; and Supplemental Table $12)^{8}$. Stance moderated the effect of receiving hybrid threat acknowledgment (vs. receiving no threat rationale) on all outcomes in both studies, with the exception of symbolic threat rejection in Study 3a (see Table 4 for interaction effects and Figure 3 for simple effects). We also found some support of moderation when comparing the Hybrid vs. Typical threat conditions: Interactions were significant for the realistic threat rejection and dehumanization outcomes in Study 3b, and the symbolic threat rejection outcome in Study 3a.

Following Hayes (2018), we estimated the simple effects of condition for people equal to the $16^{\text {th }}$ percentile in support for social distancing (i.e., relatively anti-social distancing) and for people equal to the $84^{\text {th }}$ percentile in support for social distancing (i.e., relatively prosocial distancing). Importantly, all participants operationalized as "relatively anti-social distancing" had learned about a "pro-social distancing" opponent, while all participants operationalized as "relatively pro-social distancing" had learned about an "anti-social distancing" opponent.

People Relatively Pro-Social Distancing. The intervention was effective for participants relatively pro-social distancing: Relative pro-social distancers in the Hybrid Threat Acknowledgement (vs. No Threat Rationale) condition were less likely to see opponents as rejecting realistic threat, and were less likely to morally condemn and dehumanize. Relative pro-social distancers were also less likely to think opponents rejected symbolic threat in the Hybrid vs. No Threat rationale condition - this was expected since

\footnotetext{
${ }^{8}$ See Supplemental Table $7 \& 10$ for ANCOVA results testing condition effect on outcomes, controlling for political ideology and own concern of threat.
} 
opponents described symbolic threat concerns (along with realistic threat) in the Hybrid condition, but no threat concerns in the No Threat condition.

Relatively pro-social distancers in the Hybrid Threat Acknowledgement (vs. Typical Threat Rationale) condition were less likely to morally condemn opponents in both studies, and less likely to dehumanize opponents in Study $3 \mathrm{~b}$ (effect trending in 3a). Also, as expected, relatively pro-social distancers in the Hybrid vs. Typical Threat condition were significantly less likely to view opponents as rejecting realistic threat (but did not differ in perceptions of symbolic threat).

People Relatively Anti-Social Distancing. The intervention was less effective for people relatively opposed to social distancing: There were no significant differences between relatively anti-social distancers assigned to the Hybrid Threat Acknowledgment vs. No Threat Rationale condition on any outcome. When comparing the Hybrid and Typical threat conditions, effects were non-significant with the exception that relatively anti-social distancers in the Hybrid Threat condition perceived less symbolic threat rejection in Study 3a. 
Table 4.

Moderation Analysis Testing the Condition x Participant Stance Interaction on Outcomes in

Study 3.

\begin{tabular}{|c|c|c|c|c|}
\hline & $\begin{array}{c}\text { Perception of Opponent } \\
\text { Rejection of Realistic } \\
\text { Threat } \\
b(95 \% \mathrm{CI})\end{array}$ & $\begin{array}{c}\text { Perception of Opponent } \\
\text { Rejection of Symbolic } \\
\text { Threat } \\
b(95 \% \mathrm{CI})\end{array}$ & $\begin{array}{l}\text { Moral Condemnation } \\
\quad b(95 \% \mathrm{CI})\end{array}$ & $\begin{array}{c}\text { Opponent } \\
\text { Dehumanization } \\
b(95 \% \mathrm{CI})\end{array}$ \\
\hline \multicolumn{5}{|c|}{ Study 3a } \\
\hline Hybrid vs Typical & $-0.35(-0.56,-0.13)^{* *}$ & $-0.09(-0.32,0.14)$ & $-0.20(-0.40,-0.01) \dagger$ & $-0.12(-0.34,0.10)$ \\
\hline $\begin{array}{l}\text { Hybrid vs No } \\
\text { Rationale }\end{array}$ & $-0.28(-0.50,-0.07)^{* *}$ & $-0.19(-0.43,0.04)$ & $-0.11(-0.32,0.10)$ & $-0.05(-0.27,0.17)$ \\
\hline Stance & $0.30(0.20,0.40)^{* * *}$ & $-0.03(-0.08,0.14)$ & $0.23(0.14,0.33)^{* * *}$ & $0.26(0.16,0.37)^{* * *}$ \\
\hline $\begin{array}{l}\text { Hybrid vs Typical } \\
\text { X Stance } \\
\text { Interaction }\end{array}$ & $-0.08(-0.21,0.06)$ & $0.17(0.03,0.32)^{*}$ & $-0.10(-0.23,0.04)$ & $-0.009(-0.13,0.15)$ \\
\hline $\begin{array}{l}\text { Hybrid vs No } \\
\text { Rationale X } \\
\text { Stance Interaction }\end{array}$ & $-0.22(-0.36,-0.09)^{* *}$ & $-0.13(-0.28,0.02)$ & $-0.23(-0.36,-0.09)^{* * *}$ & $-0.17(-0.31,-0.03)^{*}$ \\
\hline \multicolumn{5}{|c|}{ Study 3b } \\
\hline Hybrid vs Typical & $-0.43(-0.62,-0.25)^{* * *}$ & $-0.17(-0.38,0.03)$ & $-0.20(-0.37,-0.03)^{*}$ & $-0.35(-0.54,-0.16)^{* * *}$ \\
\hline $\begin{array}{l}\text { Hybrid vs No } \\
\text { Rationale }\end{array}$ & $-0.35(-0.54,-0.15)^{* * *}$ & $-0.29(-0.50,-0.07)^{* *}$ & $-0.22(-0.40,-0.04)^{*}$ & $-0.43(-0.63,-0.23)^{* * *}$ \\
\hline Stance & $0.20(0.12,0.28)^{* * *}$ & $-0.002(-0.09,0.09)$ & $0.21(0.13,0.29)^{* * *}$ & $0.25(0.16,0.33)^{* * *}$ \\
\hline $\begin{array}{l}\text { Hybrid vs Typical } \\
\text { X Stance } \\
\text { Interaction }\end{array}$ & $-0.22(-0.33,-0.11)^{* * *}$ & $-0.04(-0.16,0.09)$ & $-0.09(-0.19,0.02)$ & $-0.12(-0.24,-0.005)^{*}$ \\
\hline $\begin{array}{l}\text { Hybrid vs No } \\
\text { Rationale X } \\
\text { Stance Interaction }\end{array}$ & $-0.25(-0.37,-0.14)^{* * *}$ & $-0.04(-0.26,-0.003)^{*}$ & $-0.17(-0.27,-0.06)^{* *}$ & $-0.21(-0.32,-0.09)^{* * *}$ \\
\hline \multicolumn{5}{|c|}{ Note: In condition contrasts, Hybrid is the reference group (0) and the Typical and No } \\
\hline Rationale co & litions are the compar & groups $(-1) . *_{\text {indic }}$ & $p<.05, * *$ indicate & $.01, * * *$ \\
\hline
\end{tabular}



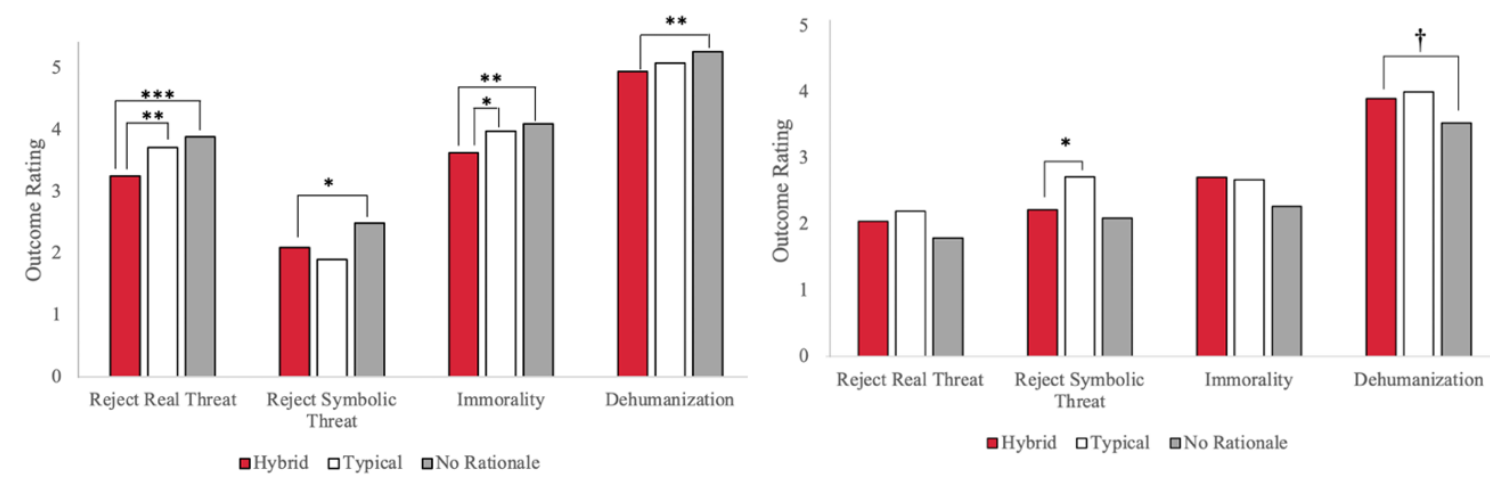

Panel C (Relatively Pro-Social Distancers; Study 3b)

Panel D (Relatively Anti-Social Distancers; Study 3b)
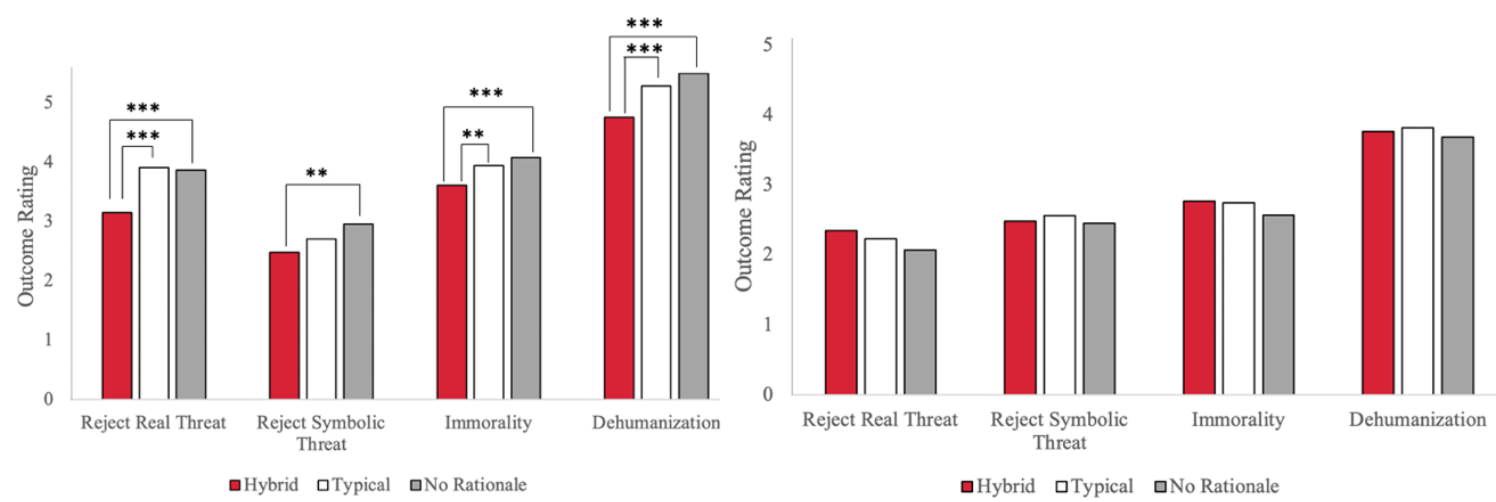

Figure 3: Estimated marginal means by condition and participant stance on social distancing. Panels A (Study 3a) and C (Study 3b) estimate means for relatively pro-social distancers $\left(84^{\text {th }}\right.$ percentile on social distancing support) ratings by condition. Panels B (Study 3a) and D (Study $3 b)$ estimate means for relatively anti-social distancers $\left(16^{\text {th }}\right.$ percentile on social distancing support) by condition. $* * *$ indicates $p<.001, * *$ indicates $p<.01$, *indicates $p<.05$, $\dagger$ indicates $p<.10$. Most participants reported being pro-social distancing and read about an anti-social distancing opponent (Study $3 \mathrm{a} N=422$, Study $3 \mathrm{~b} N=608)$. In Study $3 \mathrm{a}(N=96)$ and Study $3 \mathrm{~b}(N=146)$ participants reported being anti-social distancing and read about pro-social distancers. 
Threat Rejection, Condemnation as Mediators of Intervention. We examined whether reductions in threat rejection explained the effectiveness of the Hybrid Threat Acknowledgement intervention in reducing moral condemnation and dehumanization among those relatively pro versus anti-social distancing. Using a custom PROCESS model, we tested a moderated serial mediation model in which the Hybrid Threat Acknowledgement Intervention (versus the other conditions) indirectly impacted dehumanization by reducing realistic and/or symbolic threat rejection (entered in parallel), and in turn, moral condemnation. We included social distancing stance as a continuous moderator of the paths between condition and both types of threat rejection, the paths between condition and moral condemnation, and the paths between condition and dehumanization, as well as the paths in which realistic/symbolic threat rejection impacted condemnation and dehumanization (see Supplemental Materials p.29 for conceptual model $)^{9}$.

People Relatively Pro-Social Distancing. We found a significant serial indirect effect of condition on dehumanization via the realistic threat rejection and moral condemnation pathway when comparing the Hybrid Threat Acknowledgement condition to the Typical Threat Rationale condition (serial real indirect effectstudy $3 a=-0.11, \mathrm{SE}=0.05,95 \% \mathrm{CI}[-0.22$, 0.03]; serial real indirect effect Study $\left._{3}=-.23, \mathrm{SE}=0.05,95 \% \mathrm{CI}[-0.35,-0.15]\right)$ and the No Threat Rationale condition(serial real indirect effectstudy $3 a=-0.16, \mathrm{SE}=0.05,95 \% \mathrm{CI}[-0.26,-0.07]$; serial real indirect effect $\left.t_{\text {Study }} 3 b^{=}=-0.22, \mathrm{SE}=0.06,95 \% \mathrm{CI}[-0.34,-0.13]\right)$.

When exploring the serial indirect effects of condition on dehumanization via the symbolic threat rejection and moral condemnation pathway, we found one significant effect. In Study 3a the Hybrid Threat Acknowledgement (vs. No Threat condition) reduced perceptions of symbolic threat rejection, but symbolic threat rejection was associated with less moral condemnation, perhaps because symbolic concerns about identity inflamed people

\footnotetext{
${ }^{9}$ We tested the effect of being exposed to the Hybrid condition $(0)$ relative to the other conditions $(-1)$.
} 
relatively pro-social distancing who saw this as a barrier to protecting against realistic threat. Thus, the symbolic component of the hybrid manipulation indirectly increased dehumanization among relative pro-social distancers by reinforcing beliefs about opponents' concern for symbolic threat (serial real indirect effectstudy $3 a=0.02, \mathrm{SE}=0.01,95 \% \mathrm{CI}[0.001$, $0.05])$.

People Relatively Anti-Social Distancing. We did not find any significant serial indirect effects of condition through either realistic threat rejection or symbolic threat rejection in Study 3a. In Study 3b the serial path through realistic threat rejection was also non-significant yet being exposed to the Hybrid vs. Typical threat condition significantly reduced dehumanization among people relatively opposed to social distancing via the serial symbolic threat rejection pathway (serial real indirect effect Study $_{3 b}=-.08, \mathrm{SE}=0.04,95 \% \mathrm{CI}[-$ $.17,-.01])$. See Supplemental Table 14 for indirect effects. See Figure 4 for path coefficients of these models. 

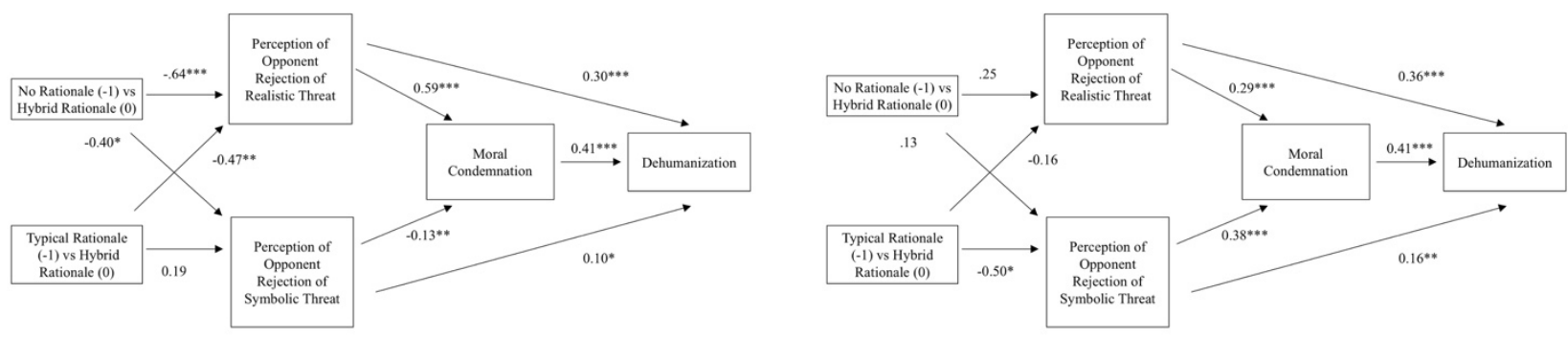

Panel C. (Relatively Pro-Social Distancers; Study 3b)

Panel D. (Relatively Anti-Social Distancers; Study 3b)
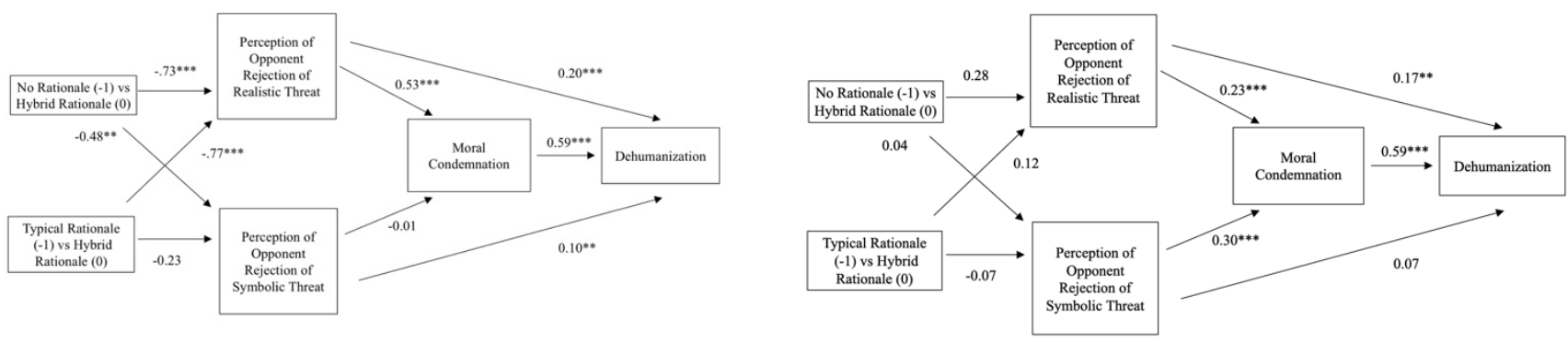

Figure 4: Moderated mediation analyses for Study 3a and Study 3b. Social distancing stance entered as continuous variable with ideology, and people's own perception of realistic and symbolic threat included as covariates. $* * *$ indicates $p<.001, * *$ indicates $p<.01, *$ indicates $p<.05$. Model paths in Panels A (Study 3a) and C (Study 3b) estimate effects for relatively pro-social distancers $\left(84^{\text {th }}\right.$ percentile on social distancing support) while model paths in Panels B (Study 3a) and D (Study 3b) estimate effects for relatively anti-social distancers ( $16^{\text {th }}$ percentile on social distancing support). We computed the indirect effects using 5,000 bootstrapping simulations. Path coefficients are unstandardized. 


\section{Discussion}

Study 3 suggests that acknowledging both realistic and symbolic threats reduces condemnation and dehumanization between policy opponents in contexts where protecting the group against realistic threat is perceived to involve the symbolic threat of cultural restriction. During COVID-19, people relatively pro-social distancing (who tend to prioritize realistic health concerns) were less likely to morally condemn and dehumanize anti-social distancers (who tend to prioritize the symbolic expression of American identity) when anti-social distancers described their fear that losing American identity might be psychologically damaging (a realistic threat). These effects were mediated by reductions in perceived realistic threat rejection.

Our intervention did not reliably reduce moral condemnation and dehumanization among people who relatively opposed social distancing. This may be because people who oppose social distancing tend to be lower in realistic threat rejection (as observed in Studies 1 and 2) than people supportive of social distancing (which all our studies indicate most inflamed dehumanization) - thus they stood less to profit from the intervention. However, our intervention also did not reliably reduce symbolic threat rejection among anti-social distancers. Further work is needed to explore other avenues for interventions to improve antisocial distancers attitudes towards opponents.

\section{General Discussion}

Does perceived threat rejection sow political divisions? Results suggest perceiving the "other side" as rejecting realistic (more than symbolic) threat increases moral condemnation and dehumanization, lending support to the asymmetry hypothesis. During COVID-19, those who relatively favored social distancing saw opponents as rejecting realistic threats and morally judged and dehumanized them. In contrast, support for social distancing did not reliably relate to perceiving the other side as rejecting symbolic threat-and symbolic threat was not robustly associated with moral judgment or dehumanization. 
Within a novel threat context, people who were more willing to sacrifice their group's culture to prevent realistic threats to health or resources viewed opponents as rejecting realistic threats and in turn morally condemned and dehumanized them. Similarly, people who were more willing to endure realistic threat to protect their culture, viewed opponents as rejecting symbolic threats, in turn morally condemning and dehumanizing them, yet these effects were significantly weaker than for realistic threat rejection. Our findings are consistent with research suggesting people condemn behaviors which are perceived as causing concrete (realistic) harm rather than abstract (symbolic) harm (Schein \& Gray 2018).

Using a threat-acknowledgement-intervention, we decreased the tendency of people who tended to prioritize protecting the group from realistic threat (i.e., those who tended to support social distancing) to morally judge and dehumanize opponents who prioritized protecting the group from symbolic threat (i.e., those who tended to resist social distancing). Our intervention did not require opponents to compromise their stance - this intervention worked by simply having opponents acknowledge both realistic and symbolic threats when providing a rationale for their position.

\section{Implications}

Our research suggests that when people disagree about important policy issues - like how their nation should respond to a global pandemic - people most driven to defend against realistic threat, tolerate their opponents more when they believe their opponents are driven by the same concerns for realistic threats.

Our research is the first to consider people's beliefs about whether out-group members reject realistic or symbolic threats. We contribute to the dehumanization literature by introducing realistic (and to a lesser extent symbolic) threat rejection as novel antecedents of this destructive intergroup process (Kteily \& Bruneau, 2017). Our findings also extend past work on intolerance, by showing that not only differences in people's moral values (e.g., 
Graham et al., 2009; Skitka et al., 2005), but also differences in perceived concern for group threats cause intergroup conflict.

\section{Limitations and Future Directions}

All studies used online self-report surveys. Four samples were convenience samples of MTurk workers (although Study $3 b$ recruited a quasi-representative sample). Additionally, all studies were conducted in the United States, meaning it is unclear whether such effects are generalizable cross-culturally, especially given differences in lockdown strictness globally, shifting citizens' evaluations of real and symbolic threats. Future research should use a greater variety of contexts (e.g., field and lab studies), behavioral measures (e.g., discussions between opponents) and replicate these effects in other countries beyond the United States. Relatedly, our intervention artificially informed people about opponents' policy rationale-something that may not occur in real interactions. Future research should develop trainings encouraging acknowledgement of the threats opponents care about, an avenue supported by other acknowledgment-based resolution strategies (Huo, et al., 2005).

Our intervention focused on comparing a hybrid realistic/symbolic threat rationale to the typical realistic (health) threat or symbolic threat rationales often associated with opposing views on social distancing (Kachanoff et al., 2021). Future work should test whether including realistic (economic) threats in interventions is similarly beneficial. Economic threats seem to resonate with both pro and anti-social distancers: anti-social distancers argued restrictions would hurt the economy (by closing businesses) while pro-social distancers argued they would protect the economy (by preventing the need for larger shut-downs; Enwemeka, 2020; Rosman et al., 2020). This approach might be helpful for anti-social distancers who were not impacted by the hybrid threat intervention tested here, and may need an alternative intervention.

\section{Conclusion}


This research provides a valuable first step for understanding how beliefs about threat rejection shape perceptions across policy lines. Our findings reveal the first step for bridging divides may be for people to signal that the reason they so strongly disagree on policy is because they hold the same concern for lives and livelihoods. 


\section{References}

Abrams, Dominic, Vasiljevic, Milica (2014) How Does Macroeconomic Change Affect Social Identity (and Vice Versa?): Insights from the European Context. Analysis of Social Issues and Public Policy, 14 (1). pp. 311-338. ISSN 1530-2415. KAR $\underline{\mathrm{id}: 46665)}$.

Bandura, A. (1999). Moral disengagement in the perpetration of inhumanities. Personality and Social Psychology Review, 3, 193-209. doi:10.1207/s15327957pspr0303_3

Bastian, B., Denson, T. F., \& Haslam, N. (2013). The roles of dehumanization and moral outrage in retributive justice. PloS one, 8(4), e61842.

Bruneau, E. G., \& Saxe, R. (2012). The power of being heard: The benefits of 'PerspectiveGiving' in the context of intergroup conflict. Journal of Experimental Social Psychology, 48(4), 855-866.

Cassese E. C. (2020). Dehumanization of the opposition in political campaigns. Social Science Quarterly, 101(1), 107-120.

Clinton, J., Cohen, J., Lapinski, J., \& Trussler, M. (2021). Partisan pandemic: How partisanship and public health concerns affect individuals' social mobility during COVID-19. Science advances, 7(2), eabd7204.

Ember, S. (2020). Biden campaign lashes Trump over concealing the danger of the virus. The New York Times. Retrieved November $16^{\text {th }} 2020$ from: https://www.nytimes.com/2020/09/10/us/politics/biden-trump-virus-woodward.html.

Enwemeka, Z. (2020). Aggressive social distancing now is good for the economy later, study finds. WBUR News. https://www.wbur.org/news/2020/04/01/social-distancingeconomic-impact-covid-19-coronavirus-spanish-flu

Esses, V. M., Dovidio, J. F., Jackson, L. M., \& Armstrong, T. L. (2001). The immigration dilemma: The role of perceived group competition, ethnic prejudice, and national identity. Journal of Social Issues, 57(3), 389-412. 
Feinberg, M., \& Willer, R. (2013). The moral roots of environmental attitudes. Psychological Science, 24(1), 56-62.

Galinsky, A. D, Ku, G., Wang, C. S. (2005). Perspective-taking and self-other overlap: Fostering social bonds and facilitating social coordination. Group Processes \& Intergroup Relations, 8(2), 109-124.

Gamez-Djokic, M., \& Waytz, A. (2020). Concerns About Automation and Negative Sentiment Toward Immigration. Psychological Science, 31(8), 987-1000.

Graham, J., Haidt, J., \& Nosek, B. A. (2009). Liberals and conservatives rely on different sets of moral foundations. Journal of Personality and Social Psychology, 96(5), 1029.

Gray, K., \& Wegner, D. M. (2011). Dimensions of moral emotions. Emotion Review, 3(3), 258-260.

Gollwitzer, A., Martel, C., Brady, W. J., Knowles, E. D., \& Van Bavel, J. (2020). Partisan Differences in Physical Distancing Predict Infections and Mortality During the Coronavirus Pandemic. Available at SSRN 3609392.

Greenaway, K. H., Cruwys, T., Haslam, S. A., \& Jetten, J. (2016). Social identities promote well-being because they satisfy global psychological needs. European Journal of Social Psychology, 46, 294-307. doi:10.1002/ejsp.2169.

Haslam, N., Bastian, B., Laham, S., \& Loughnan, S. (2012). Humanness, dehumanization, and moral psychology. In M. Mikulincer \& P. R. Shaver (Eds.), The social psychology of morality: Exploring the causes of good and evil (pp. 203-218). Washington, DC: APA Press.

Hayes, A. F. (2018). Introduction to Mediation, Moderation, and Conditional Process Analysis: A Regression-Based Approach. Guilford Press.

Huo, Y. J., Molina, L. E., Sawahata, R., \& Deang, J. M. (2005). Leadership and the management of conflicts in diverse groups: Why acknowledging versus neglecting subgroup identity matters. European Journal of Social Psychology, 35, 237-254. 
Kachanoff, F., Bigman, Y., Kapsaskis, K., \& Gray, K. (2021). Measuring two distinct psychological threats of COVID-19 and their unique impacts on wellbeing and adherence to public health behaviors. Social Psychological and Personality Science, 12(5), 603-616.

Kachanoff, F. J., Kteily, N. S., Khullar, T. H., Park, H. J., \& Taylor, D. M. (2020). Determining our destiny: Do restrictions to collective autonomy fuel collective action? Journal of Personality and Social Psychology, 119(3), 600.

Kachanoff, F. J., Taylor, D. M., Caouette, J., Khullar, T. H., Wohl, M. J. A. (2019). The chains on all my people are the chains on me: Restrictions to collective autonomy undermine the personal autonomy and psychological well-being of group members. Journal of Personality and Social Psychology, 116(1), 141- 165.

Kidwell, B., Farmer, A., \& Hardesty, D. M. (2013). Getting liberals and conservatives to go green: Political ideology and congruent appeals. Journal of Consumer Research, 40(2), 350-367.

Kteily, N. S., \& Bruneau, E. (2017). Darker demons of our nature: The need to (re) focus attention on blatant forms of dehumanization. Current Directions in Psychological Science, 26(6), 487-494.

Kteily, N., Bruneau, E., Waytz, A., \& Cotterill, S. (2015). The ascent of man: Theoretical and empirical evidence for blatant dehumanization. Journal of Personality and Social Psychology, 109(5), 901.

Louis, W. R., Esses, V. M., \& Lalonde, R. M. (2013). National identification, perceived threat, and dehumanization as antecedents of negative attitudes toward immigrants in Australia and Canada. Journal of Applied Psychology, 43, E156-E165.

Martherus, J. L., Martinez, A. G., Piff, P. K., \& Theodoridis, A. G. (2021). Party animals? Extreme partisan polarization and dehumanization. Political Behavior, 43(2), 517-540. 
Moore-Berg, S. L., Hameiri, B., \& Bruneau, E. (2020). The prime psychological suspects of toxic political polarization. Current Opinion in Behavioral Sciences, 34, 199-204.

Moran, L. (2020). 'Selfish Monster' GOP cit council member vows to defy rules at Thanksgiving. Huffington Post. Retrieved November 26, 2020 from: https://www.huffpost.com/entry/gop-coronavirus-lawmaker-ignorerules_n_5fae3df4c5b6370e7e31c91b?guccounter=1

Pacilli, M. G., Roccato, M., Pagliaro, S., \& Russo, S. (2016). From political opponents to enemies? The role of perceived moral distance in the animalistic dehumanization of the political outgroup. Group Processes \& Intergroup Relations, 19(3), 360-373.

Ritzen, J., Easterly, W., \& Woolcock. M. (2000). On 'good' politicians and 'bad' policies: Social cohesion, institutions, and growth. World Bank Policy Research Working Paper No. 2448.

Rosman, T., Chasiotis, A., Kerwer, M., Steinmetz, H., Wedderhoff, O., Betsch, C., \& Bosnjak, M. (2020). Will COVID-19-related economic worries superimpose the health worries, reducing acceptance of social distancing measures? A prospective preregistered study. ZPID (Leibniz Institute for Psychology Information). https://doi.org/10.23668/PSYCHARCHIVES.3005

Schein, C., \& Gray, K. (2018). The theory of dyadic morality: Reinventing moral judgment by redefining harm. Personality and Social Psychology Review, 22(1), 32-70.

Shear, M. D., \& Mervosh, S. (2020). Governors Who Have Imposed Virus Restrictions. New York Times. Retrieved November $16^{\text {th }} 2020$ from: https://www.nytimes.com/2020/04/17/us/politics/trump-coronavirus-governors.html.

Shweder, R. A., Much, N. C., Mahapatra, M., \& Park, L. (1997). The "big three” of morality (autonomy, community, divinity) and the "big three" explanations of suffering. Morality and Health, 119, 119-169. 
Skitka, L. J., Bauman, C. W., \& Sargis, E. G. (2005). Moral conviction: Another contributor to attitude strength or something more?.Journal of Personality and Social Psychology, 88(6), 895.

Stein, D. H., Schroeder, J., Hobson, N., Gino, F., \& Norton, M. I. (2020). When Alterations are Violations: Moral Outrage and Punishment in Response to (Even Minor) Alterations to Rituals.

Stephan, W. G., Ybarra, O., \& Rios Morrison, K. (2009). Intergroup Threat Theory (pp. 4359). Handbook of Prejudice. Mahwah, NJ: Lawrence Erlbaum Associates.

Whiting, T. M. (2020). Refusing to wear a mask isn’t defending American values but dishonoring them. Tennessean. Retrieved November $26^{\text {th }} 2020$ from: https://eu.tennessean.com/story/opinion/2020/10/27/putting-mask-not-only-protectsbut-honors-america/6045392002/ 